\title{
Are Litter Mates Needed for Each Piglet to Keep its Exclusive Teat after the Establishment of a Teat Order?
}

\author{
Toshio TANAKA, Miyako KAWARAZAKI and Tadashi YOSHIMOTO \\ School of Veterinary Medicine, Azabu University, Sagamihara-shi 229-8501, Japan
}

(Received April 19, 2000; Accepted September 13, 2000)

\begin{abstract}
Experiments were conducted to investigate how piglets discriminate between their exclusive teats on their dam's udder after the establishment of a teat order. Thirteen piglets from two litters were used. All piglets were tested from 1 to 3 weeks of age in the following two experiments. Experiment 1: When the sow grunted to indicate suckling, her litter was moved to the next pen. The piglets were housed one by one in a starting box placed at the back of the lying sow. After a short period, the door of the box was opened and each piglet started to seek its dam's udder without its litter mates. Experiment 2 : When the sow grunted to indicate suckling, her litter was moved to the next pen. The front teats, on both the left-hand and the right-hand sides, were covered by an elastic cloth which was skin color. The piglets were housed in a starting box placed at the back of the lying sow. After a short period, the door of the box was opened and the piglets started to seek their dam's udder. In experiment $1,76.9 \%$ of the piglets were able to reach their dam's udder within $3 \mathrm{~min}$, and $83.3 \%$ of them reached their exclusive teats $(\mathbf{P}<0.01)$. In experiment 2 , the piglets that had occupied the front teats could not find their teats since they were covered with a cloth. The piglets were in a flurry and did not reach any other teats. All the other piglets were able to reach their proper teats within 3 min. These results indicate that piglets might be able to discriminate between their exclusive teats from other teats in an absolute position, but not in a position relative to other litter mates.

Animal Science Journal 71 (6) : 609-613, 2000
\end{abstract}

Key words : Piglets, Teat order, Teat seeking behavior, Litter mates

Newborn piglets show a strong tendency to preferentially occupy the anterior teats. However, most piglets return to the same part of the udder and fix onto their one or two exclusive teats during the first few days. The consistent position which piglets occupy on the udder is generally called the teat order $^{8)}$.

Piglets usually have to find a teat without the assistance of their dam. Therefore, their auditory, visual, olfactory and tactile senses are well developed immediately after birth ${ }^{6}$. The teat seeking behavior of the piglets requires a wide variety of sensory cues ${ }^{2-4,10)}$. We have shown that the visual stimulus is the most important aspect of teat seeking behavior by the piglets, and that olfactory interception has a lesser effect than the visual and auditory senses ${ }^{93}$. Howev- er, the relative importance of the existence of litter mates to keep their teat order has not been studied.

The objective of the present experiment was to investigate how piglets discriminate between their exclusive teats on their dam's udder, especially the relative importance of the existence of litter mates, after the establishment of a teat order.

\section{Materials and Methods}

\section{Animals and experimental period}

Experiments were carried out to investigate how piglets discriminate between their exclusive teats on their dam's udder after the establishment of a teat order ( 7 days of age). Thirteen crossbred piglets (Landrace $\times$ Large White $\times$ Duroc) from two litters were used. Litter 1 consisted 4 males and 6 females,

Corresponding : Toshio Tanaka (fax : +81 (0) 42-769-1692, e-mail : tanakat@azabu-u.ac.jp)

Anim. Sci. J. 71 (6) : 609-613, 2000 
TANAKA, KAWARAZAKI and YOSHIMOTO

Table 1. Time spent on teat seeking behavior in Exp. 1 (min'sec)

\begin{tabular}{|c|c|c|c|c|c|}
\hline \multicolumn{2}{|c|}{ Individual No. } & \multirow{2}{*}{$\frac{1 \text { st wk }}{I^{\prime} 33}$} & \multirow{2}{*}{$\frac{2 \mathrm{nd} w \mathrm{wk}}{l^{\prime} 41^{*}}$} & \multirow{2}{*}{$\frac{3 \mathrm{rd} \mathrm{wk}}{1^{\prime} 29^{*}}$} & \multirow{2}{*}{$\frac{\text { mean }}{l^{\prime} 34}$} \\
\hline Litter 1 & $1-1$ & & & & \\
\hline & $1-2$ & $2^{\prime} 31$ & $1^{\prime} 48$ & $N$ & $2^{\prime} 10$ \\
\hline & $1-3$ & 1'56 & $N$ & $2^{\prime} 20^{*}$ & $2^{\prime} 08$ \\
\hline & $1-4$ & $l^{\prime} 04$ & $N$ & $1^{\prime} 38$ & $l^{\prime} 21$ \\
\hline & $1-5$ & $N$ & $l^{\prime} 46$ & $2^{\prime} 10$ & $1 ' 58$ \\
\hline & $1-6$ & $2^{\prime} 46$ & $l^{\prime} 45^{*}$ & $1^{\prime} 46^{*}$ & $2^{\prime} 06$ \\
\hline & $1-7$ & I'56 & $2^{\prime} 28$ & $1^{\prime} 46$ & $2^{\prime} 03$ \\
\hline & mean & $1^{\prime} 58$ & $2^{\prime} 01$ & $I^{\prime} 51$ & $I^{\prime} 54 \pm^{\prime} 26$ \\
\hline \multirow[t]{7}{*}{ Litter 2} & $2-1$ & $N$ & $l^{\prime} 31$ & $1^{\prime} 23$ & $1^{\prime} 27$ \\
\hline & $2-2$ & $1 ' 14$ & $2^{\prime} 22$ & $I^{\prime} 09$ & $1^{\prime} 35$ \\
\hline & $2-3$ & $N$ & $2^{\prime} 48$ & $N$ & $2^{\prime} 48$ \\
\hline & $2-4$ & $1^{\prime} 42$ & $1^{\prime} 08$ & $1^{\prime} 11$ & $l^{\prime} 20$ \\
\hline & $2-5$ & $2^{\prime} 28$ & $2^{\prime 32}$ & $2^{\prime} 12$ & $2^{\prime} 24$ \\
\hline & $2-6$ & $N$ & $N$ & $2^{\prime} 48$ & $2^{\prime} 48$ \\
\hline & mean & $I^{\prime} 48$ & $2^{\prime} 04$ & $1^{\prime} 45$ & $I^{\prime} 53 \pm^{\prime} 40$ \\
\hline
\end{tabular}

*, reached another (not exclusive) teat.

$N$, did not reach any teats.

and 7 healthy piglets ( 2 castrated males and 5 females) of them were used. Litter 2 consisted 5 males and 3 females, and healthy 4 castrated males and 2 females of them were used. All piglets were tested from 1 to 3 weeks of age, one session per week, in the following two experiments. Experiments 1 and 2 were done on every Monday and Thursday morning, respectively. Both experiments were conducted in the farrowing crate $(210 \mathrm{~cm} \times 223 \mathrm{~cm})$ with a feeder and a waterer for the sow and a feeder and a heater for the piglets.

\section{Experiment 1}

When the sow grunted to indicate suckling, her litter was moved to the next pen. The piglets were housed one by one in a starting box $(40 \times 45 \times 40 \mathrm{~cm})$ placed at the back of the lying sow. After a short period $(<1 \mathrm{~min})$, the door of the box was opened and each piglet started to seek its dam's udder without its litter mates.

The piglets' behavior was observed directly for 3 min by the experimenter behind the starting box. The route used and time spent on teat seeking were recorded for each piglet. The number of piglets which could not reach their dams' teats in 3 min was also counted. Piglets generally reached their dams' teats and sucked in less than $1 \mathrm{~min}$, and there was no case that the teat seeking took more than $3 \mathrm{~min}$ in the pre-experiment. Therefore, one session lasted $3 \mathrm{~min}$.

\section{Experiment 2}

When the sow grunted to indicate suckling, her litter was moved to the next pen. The front two teats, on both the left-hand and the right-hand sides, were covered by a belt of elastic cloth, the color of skin. The piglets were housed in a starting box placed at the back of the lying sow. After a short period $(<1 \mathrm{~min}$ ), the door of the box was opened and the piglets started to seek their dam's udder.

The piglets' behavior was observed for $3 \mathrm{~min}$ using the same method as experiment 1. The route used and time spent on teat seeking were recorded for each piglet. The teat number each piglet occupied was also recorded.

\section{Results}

\section{Experiment 1}

The time spent on teat seeking behavior, and the number of piglets which were able to reach their dam's 


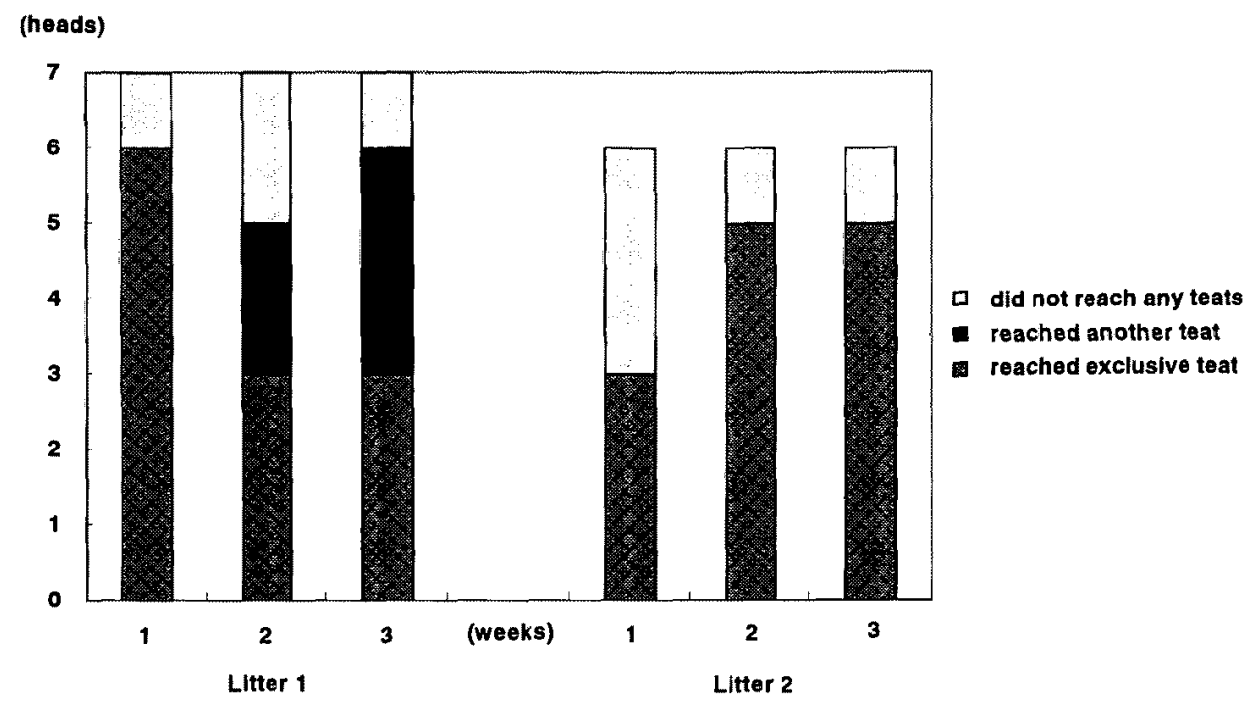

Fig. 1. The number of piglets which were able to reach their dam's udder within $3 \mathrm{~min}$ in Exp. 1.

udder are shown in Table 1 and Fig. 1, respectively. In Litter 1, six, five and six out of seven piglets reached the udder at the first, second and third week, respectively. These piglets took $64-166 \mathrm{sec}$ (mean $114 \pm 26 \mathrm{sec}$ ) to reach the teats. In Litter 2, three, five and five out of six piglets reached there at each week, respectively. They took $68-168 \mathrm{sec}$ (mean $113 \pm 40 \mathrm{sec})$ to reach the teats. In total, $76.9 \%(30 /$ 39) of the piglets were able to reach their dam's udder within $3 \mathrm{~min}$, and $83.3 \%(25 / 30, \mathrm{P}<0.01)$ of them reached their exclusive teats.

\section{Experiment 2}

Table 2 shows the teat numbers which were occupied by each piglet. The piglets that had occupied the front teats (Piglets No. 1-4, No. 1-7 and No. 2-5) started for their teats and hung around there, but could not find their teats since they were covered with a cloth. These piglets were in a flurry and did not reach any other teats (Fig. 2). All the other piglets were able to reach their proper teats within 3 min.

\section{Discussion}

For most of the piglets, teat order becomes stable 7 days after birth, regardless of the litter size. Sex, birth weight and birth order have no influence on teat order $^{7)}$. On the other hand, Miyakoshi et al. ${ }^{5)}$ reported that the heavier piglets tended to occupy the anterior teats. And he showed that $98 \%$ of the piglets established their individual teat order by 3 days of age ${ }^{5)}$. However, if a piglet that had occupied the anterior teats died, the litter mates moved to the frontal teat positions, and the teat order was reformed. This suggests that teat order is affected by the existence and/or absence of litter mates.

In experiment 1 in this study, most of the piglets sucked their exclusive teats even if all teats were available when they sucked without litter mates. Some piglets, however, reached the other teats, but most of them were adjoining teats. This means that the piglets are able to discriminate their exclusive teats from others without litter mates, and have a tendency to suck them.

In experiment 2 , if the relative positions of piglets were important for them to keep their teat order, the piglets that had occupied the front teats should reach the second teats and the other piglets shifted to next ones. However, those piglets hung around their dam's udder, and they did not reach any teats in spite of the second teats were not occupied by others in most cases. This means that the piglets might not keep their teat order as a relationship between the next 
TANAKA, KAWARAZAKI and YOSHIMOTO

Table 2. Teat numbers which were occupied by each piglet in Exp. 2

\begin{tabular}{|c|c|c|c|c|c|c|}
\hline \multicolumn{2}{|c|}{ Individual No. } & \multicolumn{2}{|c|}{ Exclusive teats ${ }^{1)}$} & \multicolumn{3}{|c|}{ Reached teats ${ }^{2)}$} \\
\hline & & Right & Left & $1 w(L)$ & $2 \mathrm{w}(\mathrm{R})$ & $3 w(R)$ \\
\hline \multirow[t]{8}{*}{ Litter 1} & $1-1$ & L 5, L 6 & R6 & R6 & L5 & L6 \\
\hline & $1-2$ & R 3 & L3 & L 3 & R3 & R3 \\
\hline & $1-3$ & $\mathrm{~L} 7, \mathrm{R} 7$ & R 7 & R 7 & L 7 & R 7 \\
\hline & $I-4$ & L 1 & R I & $N$ & $N$ & $N$ \\
\hline & $1-5$ & L 3 & $\mathbf{R} 2, \mathbf{R} 3$ & R 3 & L3 & L3 \\
\hline & $1-6$ & L 2, R 2 & L5, R5 & R 5 & $\mathrm{~L} 2$ & $\mathbf{L} 2$ \\
\hline & $1-7$ & R I & Ll & $N$ & $N$ & $N$ \\
\hline & & Right & Left & I w (L) & $2 \mathrm{w}(\mathbf{R})$ & $3 w(L)$ \\
\hline \multirow[t]{6}{*}{ Litter 2} & $2-1$ & L 5, R 5 & L5, R5 & L5 & L5 & $\mathbf{R} 5$ \\
\hline & $2-2$ & L 7 & L7 & $\mathrm{L} 7$ & L 7 & L 7 \\
\hline & $2-3$ & $\mathbf{R} 2, \mathbf{R} 3$ & $\mathbf{L} 2, \mathbf{L} 3$ & L3 & $\mathbf{R} 2$ & L3 \\
\hline & $2-4$ & $\mathbf{L} 4, \mathbf{L} 5$ & $\mathrm{~L} 4, \mathbf{R} 4$ & L 4 & $\mathbf{L} 4$ & R 4 \\
\hline & $2-5$ & $\mathrm{R} I$ & $\mathbf{R} 1, \mathbf{R} 2$ & $\mathbf{R} 2$ & $N$ & $N$ \\
\hline & $2-6$ & $\mathbf{L} 2, \quad \mathbf{L} 3$ & $\mathbf{R} 3, \mathbf{R} 4$ & R 4 & L3 & L2 \\
\hline
\end{tabular}

1) Exclusive teat numbers occupied by 7-day old piglets when the dams lay on their both sides.

2) Teat numbers occupied by each piglet in Exp. 2 .

$\mathrm{L}$, left ; $\mathrm{R}$, right ; $1-7$, order from the front $N$, did not reach any teats.

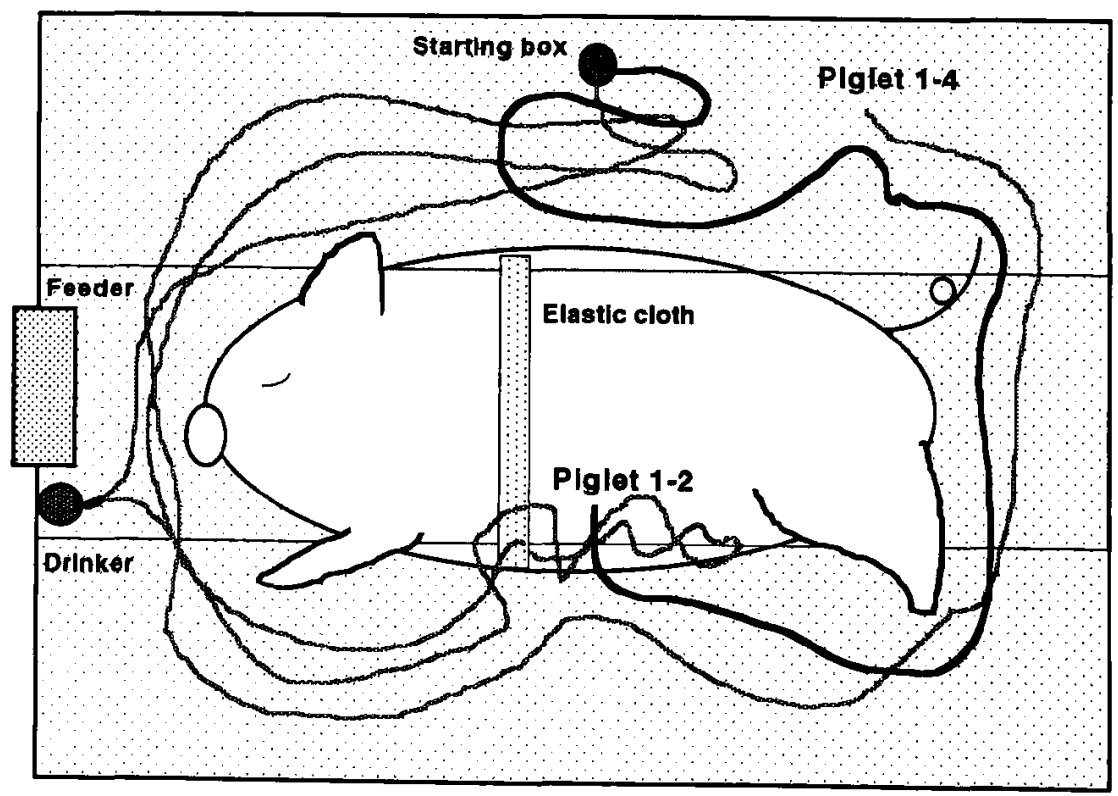

Fig. 2. The examples of the route used for teat seeking behavior of piglets that had occupied the front teats in Exp. 2. 
How Piglets Keep their Teat Order

ones.

On the basis of these results, it was concluded that the piglets might be able to discriminate between their exclusive teats from other teats in an absolute position, but not in a position relative to other litter mates after the establishment of a teat order. We have shown that the visual stimulus is the most important aspect of teat seeking behavior by the piglets aged 5-12 days ${ }^{9}$. Therefore, the piglets might find their exclusive teats with the help of a feature and/or relative positions of the teats themselves.

In addition, these findings agree with the previous results $^{\text {7) }}$ that the piglets have a tendency to fix their exclusive teats just after birth, but it takes about 7 days to establish a stable teat order. However, we observed only 2 litters which consisted small number of piglets. Hemsworth et $a l^{13}$. showed that the litter size affected on the stability of teat order. Therefore, the difference between the results of Miyakoshi et al. ${ }^{53}$ and this study should be attributed to the difference of the piglets' age and litter size.

Additional research will be need to clarify the various factors of how piglets keep their teat order.

\section{References}

1) Hemsworth PH, Winfield CG, Mullany PD. A study of the development of the teat order in piglets. $A p$ plied Animal Ethology, 2 : 225-233. 1976.

2) Jeppsen LE. Teat-order in groups of piglets on an artificial sow. I. Formation of teat order and influence of milk yield on teat preference. Applied Animal
Ethology, $8: 335-345.1982$.

3) Jeppsen LE. Teat-order in groups of piglets on an artificial sow. II. Maintenance of teat-order with some evidence for the use of odour cues. Applied Animal Ethology, 8 : 347-355. 1982.

4) McBride G. The 'teat order' and communication in young pigs. Animal Behavior, 11 : 53-56. 1963.

5) Miyakoshi Y, Shuji Y, Nagumo T, Kuroda Y, Kondo $\mathrm{Y}$, Kondo K, Tada K. A study on sucking behaviour in piglets. I. Effects of birth weight on the teat-order and the amount of milk intake. The Japanese Journal of Swine Science, 26 : 203-210. 1989. (in Japanese with English abstract)

6) Rohde Parfet KA, Gonyou HW. Attraction of newborn piglets to auditory, visual, olfactory and tactile stimuli. Journal of Animal Science, 69 : 125-133. 1991.

7) Rosillon-Warnier A, Paquay R. Development and consequences of teat-order in piglets. Applied Animal Behaviour Science, 13 : 47-58. 1984.

8) Signoret JP, Baldwin BA, Fraser D, Hafez ESE. The behaviour of swine. In: The Behaviour of Domestic Animals. (Hafez ESE ed.) 3rd ed. 295-329. Bailliere Tindall, London. 1975.

9) Tanaka T, Ochiai N, Tanida H, Yoshimoto T. The role of visual, auditory, and olfactory stimuli in teat seeking behavior of piglets. Animal Science and Technology, $69: 854$ 860. 1998.

10) Welch AR, Baxter MR. Responses of newborn piglets to thermal and tactile properties of their environment. Applied Animal Behaviour Science, 15 : 203-215. 1986. 